University of Nebraska - Lincoln

DigitalCommons@University of Nebraska - Lincoln

1982

\title{
Threshold Friction Velocities and Rupture Moduli for Crusted Desert Soils for the Input of Soil Particles into the Air
}

\author{
Dale A. Gillette \\ National Oceanic and Atmospheric Administration \\ John Adams \\ Bureau of Land Management \\ Daniel R. Muhs \\ University of Wisconsin, dmuhs@usgs.gov \\ Rolf Kihl \\ University of Colorado
}

Follow this and additional works at: https://digitalcommons.unl.edu/usgsstaffpub

Part of the Earth Sciences Commons

Gillette, Dale A.; Adams, John; Muhs, Daniel R.; and Kihl, Rolf, "Threshold Friction Velocities and Rupture Moduli for Crusted Desert Soils for the Input of Soil Particles into the Air" (1982). USGS Staff -- Published Research. 163.

https://digitalcommons.unl.edu/usgsstaffpub/163

This Article is brought to you for free and open access by the US Geological Survey at DigitalCommons@University of Nebraska - Lincoln. It has been accepted for inclusion in USGS Staff -- Published Research by an authorized administrator of DigitalCommons@University of Nebraska - Lincoln. 


\title{
Threshold Friction Velocities and Rupture Moduli for Crusted Desert Soils for the Input of Soil Particles into the Air
}

\author{
Dale A. Gillette, ${ }^{1}$ John Adams, ${ }^{2}$ Daniel Muhs, ${ }^{3}$ And Rolf $\mathrm{Kihl}^{4}$
}

\begin{abstract}
Desert soils having clay crusts, mostly from the Mojave Desert, were tested for threshold friction velocity (the friction velocity at which soil erosion begins) with an open-bottomed wind tunnel. The soils were also tested for content of clay, water-soluble material, calcium carbonate, organic material, mineralogy of clay and of salts, soil moisture, modulus of rupture, and crust thickness. If no loose material existed on the soil surface, crusts having modulus of rupture greater than 0.7 bar and crust thickness of $0.7 \mathrm{~cm}$ to $0.3 \mathrm{~cm}$ were effective in protecting against wind erosion. Disturbed clay crusts having modulus of rupture before disturbance greater than 2 bar with thickness less than $1.9 \mathrm{~cm}$ did not experience significant wind erosion. Modulus of rupture was related to composition of soil but was shown to depend mostly on clay content. Soil composition is related to modulus of rupture in an empirical equation.
\end{abstract}

\section{INTRODUCTION}

This paper follows the work of Gillette et al. [1980] on threshold friction velocities for wind erosion (the friction velocities at which soil erosion begins) of natural soils of the desert. That paper filled a void in reported measurements for threshold velocities of natural surfaces in the desert and generalized the results to other surfaces. The main concern was threshold velocities for sandy soils, and its principal conclusion was that the threshold velocity could be predicted if the mode of mass-size distribution were known for the loose particles existing on the surface. It was also concluded that clay-crusted soils in an undisturbed condition were very effective in resisting wind erosion and were effective to varying degrees after disturbance, according to the mode of the mass-size distribution. For soils with more than $90 \%$ by mass of sand, disturbed threshold lay between friction velocities of 20 to $60 \mathrm{~cm} \mathrm{~s}^{-1}$.

Here we describe supplementary tests to illuminate relations of soil composition and friction velocity for undisturbed and disturbed soils having high clay content.

\section{Methods}

A portable wind tunnel described by Gillette [1978] was used with an open-floored test section so that a variablespeed turbulent boundary layer could be formed over a flat soil containing small-scale roughness elements. The wind tunnel used a two-dimensional 5: 1 contraction section with a honeycomb flow straightener and a roughly conical diffuser attached to the working section in a configuration similar to that described by Wooding [1968]. Dimensions of the cross section of the working section are $15.24 \times 15.24 \mathrm{~cm}$, and the length of the working section is $240 \mathrm{~cm}$.

Wind speed data were collected at several heights above the surface midway across the end of the working section. The Pitot tube anemometer was calibrated and corrected for

\footnotetext{
${ }^{1}$ Geophysical Monitoring for Climate Change, Air Resources Laboratory, National Oceanic and Atmospheric Administration, Boulder, Colorado 80303.

${ }^{2}$ Bureau of Land Management, Riverside, California 92507.

3 University of Wisconsin, Madison, Wisconsin 53706.

${ }^{4}$ University of Colorado, Boulder, Colorado 80309.
}

This paper is not subject to U.S. copyright. Published in 1982 by the American Geophysical Union.

Paper number $2 \mathrm{C} 1108$. temperature and pressure changes. Data for the mean velocity $U$ versus height $z$ (wind profile data) were fitted to the function for aerodynamically rough flow [see Priestley, 1959] using a nonlinear least squares routine

$$
U=\frac{U_{*}}{k} \ln \left(\frac{z}{z_{0}}\right)
$$

where $U_{*}$ is friction velocity, $z_{0}$ is roughness height characteristic of the surface, and $k$ is Von Kármán's constant. The threshold velocity profile was obtained when continuous movement of grains was first visible. Threshold velocities and aerodynamic roughness heights are reported in terms of the friction velocity and the roughness height. Threshold friction velocity $U_{*}$ will hereinafter be called threshold velocity.

Soil descriptions. Several representative crusted soils were chosen in the Mojave Desert. A few additional soils from other locations were chosen when certain dry soils were not available in the Mojave. All soil samples were tested in both undisturbed and disturbed states. The disturbance was caused by driving a three-quarter-ton pickup truck over the soil. The tires were of nobby tread design, and the truck was accelerated which resulted in loosening, mixing, and displacing of the surface material. The wind tunnel was placed directly over the disturbed soil (parallel to the track) so that the exposed soil was homogeneous.

The soils were classified in the field to fit roughly into three groups: crusts having a high salt content (I), clay crusts (III), and sandy soils (IV) (Table 1). Groups I and III had similar formation, being deposited at the lowest local elevations by low-energy (slow-moving) water. They differ mainly in mineralogy and availability of evaporitic minerals. Group IV is represented by only four samples since the threshold velocities for this group were the subject of a previous paper [Gillette et al., 1980]. The samples are sandy soils that were deposited at elevations between the pediments and the basins (dry lakes or playas) that were the locations for groups I and III.

Mass percentages and size distributions of the test soils were determined after water-soluble material, calcium carbonate, and organic material were removed (Table 2). The pipette method and sedigraph method were used to determine the size distributions.

Other components of the test soils are given in Table 3. 
TABLE 1. Geomorphological Settings, and Localities for Threshold Velocity Tests

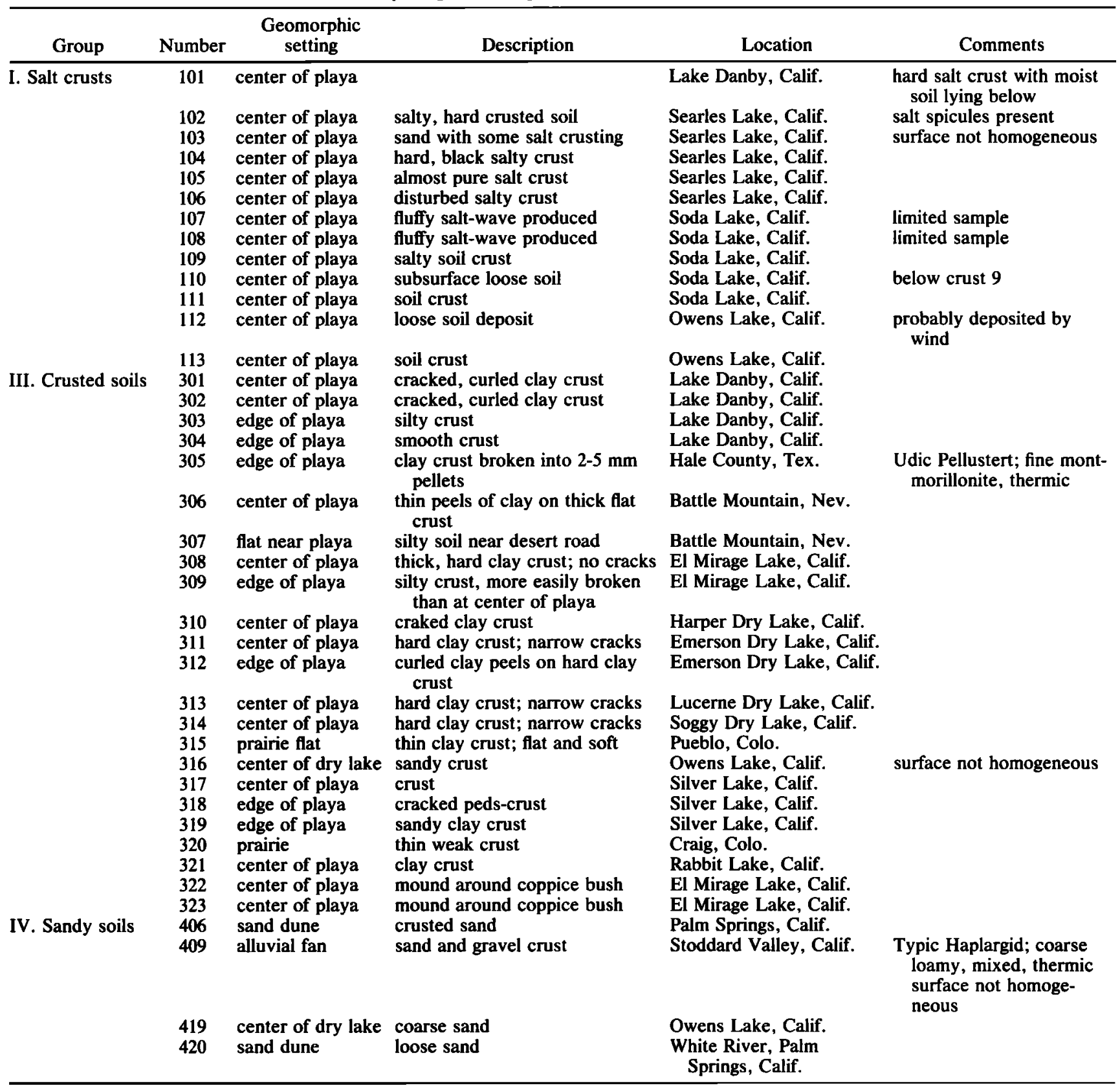

Soluble material was measured gravimetrically from a soil water extract of a suspension formed by intermittent stirring of soil in water for 3 hours. The measurement was checked (with good agreement) against specific conductance, which was converted to an estimate of soluble material by using an empirical formula. The $p \mathrm{H}$ values, organic matter, and carbonate were determined by standard laboratory procedures. Soil moisture is reported for surface samples of all test soils. Except for I-1, our desert test soils were extremely dry since they had not received moisture for months and were subject to intense heating during the day so that soil temperature often exceeded $40^{\circ} \mathrm{C}$. Several soil moisture contents were compared in terms of soil moisture at -15 bars tension (roughly the soil moisture at the wilting point of sunflowers). It was found that most soil moistures were below that of the -15 bar level. Consequently, the effect of soil moisture was ruled out as a significant variable in determining threshold velocity due to Chepils' [1956] finding that soil moisture has little effect on wind erosion if it is in amounts much less than that for -15 bars tension. Table 3 also gives mass percentages for cobbles, pebbles, and granules.

For the chemical and mineralogical determinations, airdry samples were gently disaggregated, passed through a 2$\mathrm{mm}$ sieve, and mechanically split into two subsamples. One subsample was ground to a fine powder, packed in a random mount wedge, and $X$ rayed from $2^{\circ}$ to $35^{\circ}(2 \theta)$ to determine the mineralogy of the salts. Minerals were identified according to Chao [1969]; quantitative estimates in tenths were based on a comparison of the heights of the most intense peaks (Table 4).

The second subsample was placed in a plastic centrifuge tube, where carbonates and soluble salts were removed with IN NaOAc $(p H=5)$, by use of Jackson's [1975] centrifuge 
TABLE 2. Mass Size Distribution of Test Soils

\begin{tabular}{|c|c|c|c|c|c|c|c|c|c|c|c|c|c|}
\hline ID & $\begin{array}{l}2000 \\
1000\end{array}$ & $\begin{array}{r}1000 \\
500\end{array}$ & $\begin{array}{l}500 \\
250\end{array}$ & $\begin{array}{l}250 \\
125\end{array}$ & $\begin{array}{r}125 \\
63\end{array}$ & $\begin{array}{c}63 \\
31.2\end{array}$ & $\begin{array}{l}31.2 \\
15.6 \\
\end{array}$ & $\begin{array}{r}15.6 \\
7.8\end{array}$ & $\begin{array}{l}7.8 \\
3.9\end{array}$ & $\begin{array}{r}3.9 \\
1.95\end{array}$ & $\begin{array}{l}1.95 \\
0.98\end{array}$ & $\begin{array}{l}0.98 \\
0.49\end{array}$ & $\begin{array}{l}\text { Less } \\
0.49\end{array}$ \\
\hline 101 & 0.23 & 0.9 & 1.5 & 4.9 & 18.6 & 35.0 & 9.3 & 4.2 & 3.2 & 3.1 & 3.4 & 3.9 & 11.8 \\
\hline 102 & 0.5 & 1.3 & 4.1 & 13.4 & 20.3 & 23.4 & 11.0 & 4.6 & 3.0 & 2.1 & 2.3 & 2.8 & 11.2 \\
\hline 103 & 0.6 & 3.3 & 13.3 & 25.8 & 31.5 & 19.0 & 3.3 & 0.8 & 0.2 & 0.2 & 0.2 & 0.2 & 1.5 \\
\hline 104 & 0.29 & 0.8 & 2.6 & 10.7 & 22.4 & 35.5 & 14.2 & 4.0 & 1.7 & 0.8 & 0.8 & 0.6 & 5.5 \\
\hline 105 & 0.0 & 0.3 & 0.6 & 2.8 & 6.4 & 10.3 & 8.4 & 6.3 & 4.6 & 4.2 & 5.5 & 10.5 & 40.1 \\
\hline 106 & 0.6 & 1.2 & 2.6 & 6.1 & 8.7 & 9.7 & 5.2 & 4.8 & 5.2 & 7.4 & 8.9 & 11.5 & 28.2 \\
\hline 107 & 0.0 & 0.11 & 0.06 & 0.17 & 0.45 & 2.1 & 0.5 & 2.5 & 7.4 & 14.8 & 20.2 & 21.7 & 30.1 \\
\hline 108 & 0.0 & 0.07 & 0.04 & 0.18 & 1.2 & 2.7 & 1.0 & 2.4 & 7.7 & 15.9 & 21.7 & 21.2 & 26.0 \\
\hline $109 a$ & 0.1 & 0.07 & 0.38 & 3.2 & 7.2 & 7.3 & 2.1 & 4.7 & 11.4 & 16.1 & 12.7 & 9.7 & 25.0 \\
\hline $109 b$ & 0.7 & 0.8 & 1.1 & 3.0 & 6.6 & 8.4 & 2.9 & 4.6 & 12.5 & 16.6 & 13.3 & 11.2 & 18.3 \\
\hline 110 & 0.12 & 0.32 & 0.7 & 2.2 & 5.3 & 6.4 & 3.5 & 3.9 & 12.7 & 17.1 & 13.6 & 10.5 & 23.6 \\
\hline 111 & 0.15 & 0.6 & 2.3 & 9.6 & 14.6 & 9.8 & 3.6 & 4.3 & 9.6 & 12.2 & 10.6 & 8.9 & 13.9 \\
\hline 112 & 1.5 & 1.7 & 3.6 & 13.8 & 31.6 & 19.9 & 9.3 & 4.1 & 2.6 & 2.9 & 1.9 & 3.1 & 4.1 \\
\hline 113 & 0.07 & 0.39 & 1.2 & 9.1 & 25.1 & 23.7 & 14.1 & 6.4 & 5.1 & 4.5 & 1.9 & 3.2 & 5.1 \\
\hline 301 & 0. & 0.44 & 3.1 & 5.2 & 5.0 & 1.7 & 1.1 & 2.2 & 7.5 & 12.0 & 14.2 & 12.4 & 35.3 \\
\hline 302 & 0. & 0.02 & 0.02 & 0.05 & 0.19 & 0.32 & 0.6 & 2.8 & 8.5 & 11.7 & 15.5 & 15.7 & 44.6 \\
\hline 303 & 0. & 0.0 & 0.04 & 1.6 & 5.3 & 33.6 & 19.8 & 9.9 & 6.3 & 4.1 & 3.7 & 3.2 & 12.3 \\
\hline $304 a$ & 0.45 & 1.9 & 4.1 & 9.9 & 17.3 & 12.4 & 6.3 & 8.1 & 7.9 & 6.7 & 6.1 & 5.8 & 13.0 \\
\hline $304 b$ & 1.1 & 3.6 & 6.6 & 13.2 & 23.4 & 19.1 & 3.9 & 3.6 & 3.5 & 3.4 & 3.8 & 4.1 & 10.7 \\
\hline 305a & 0. & 0. & 0.05 & 0.2 & 0.17 & 0.33 & 1.3 & 2.4 & 4.2 & 5.6 & 6.7 & 5.6 & 73.5 \\
\hline $305 b$ & 0. & 0. & 0.5 & 4.6 & 6.6 & 15. & 8. & 4.9 & 4.8 & 4.1 & 4.8 & 4.0 & 42.6 \\
\hline 306 & 0.10 & 0.20 & 0.5 & 1.1 & 2.2 & 7.0 & 5.4 & 4.3 & 6.3 & 9.1 & 18.9 & 26.5 & 18.5 \\
\hline 307 & 1.5 & 3.5 & 8.6 & 9.9 & 11.7 & 29.0 & 13.1 & 6.3 & 4.9 & 3.5 & 3.5 & 2.3 & 2.2 \\
\hline 308 & 0.04 & 0.20 & 0.7 & 3.7 & 6.5 & 4.9 & 2.8 & 5.9 & 11.8 & 11.9 & 11.9 & 13.1 & 26.5 \\
\hline 309 & 0.32 & 1.1 & 1.7 & 4.6 & 6.6 & 7.6 & 9.9 & 18.5 & 18.1 & 10.1 & 6.9 & 5.8 & 8.8 \\
\hline 310 & 0.31 & 0.6 & 1.3 & 2.9 & 3.5 & 2.9 & 2.1 & 5.1 & 8.7 & 12.6 & 15.1 & 14.2 & 30.6 \\
\hline 311 & 0.39 & 0.9 & 0.17 & 5.7 & 10.7 & 9.5 & 3.9 & 5.0 & 8.0 & 9.9 & 11.1 & 10.9 & 22.1 \\
\hline 312 & 0.05 & 0.15 & 0.41 & 2.1 & 5.8 & 7.5 & 7.4 & 10.1 & 15.0 & 13.2 & 10.3 & 8.6 & 19.4 \\
\hline 313 & 0.2 & 0.29 & 0.5 & 1.3 & 2.8 & 4.1 & 3.0 & 3.4 & 7.3 & 13.6 & 22.0 & 20.6 & 20.7 \\
\hline 314 & 0.00 & 0.18 & 1.1 & 6.1 & 10.1 & 7.6 & 3.2 & 4.3 & 7.6 & 9.9 & 13.6 & 15.8 & 20.5 \\
\hline $315 a$ & 0.09 & 0.31 & 3.8 & 10.5 & 20.8 & 31.7 & 6.0 & 2.4 & 2.1 & 2.0 & 2.3 & 2.7 & 15.4 \\
\hline $315 b$ & 0.13 & 0.39 & 3.9 & 9.9 & 22.3 & 30.3 & 5.7 & 2.9 & 2.4 & 2.1 & 2.4 & 1.9 & 15.7 \\
\hline 316 & 24.2 & 28.9 & 7.7 & 12.4 & 16.4 & 3.6 & 3.5 & 0.95 & 0.95 & $\mathbf{0 . 0}$ & 0.0 & 0.0 & (1.3) \\
\hline 317 & 0. & 1.1 & 7.7 & 7.6 & 5.8 & 3.7 & 1.9 & 1.1 & 5.6 & 12.4 & 18.0 & 15.8 & 19.2 \\
\hline 318 & 0.03 & 1.5 & 8.6 & 11.1 & 7.8 & 1.8 & 0.3 & 0.3 & 0.7 & 6.3 & 19.6 & 20.3 & 21.7 \\
\hline 319 & 0.48 & 22.1 & 29.6 & 14.1 & 9.7 & 1.5 & 0.5 & 0.1 & 0.2 & 1.5 & 5.2 & 6.5 & 8.6 \\
\hline 320 & 0.02 & 0.1 & 2.8 & 33.4 & 24.6 & 11.4 & 6.6 & 2.8 & 2.2 & 1.9 & 1.6 & 1.7 & 10.8 \\
\hline 321 & 0.32 & 1.0 & 2.5 & 8.5 & 11.1 & 8.7 & 2.1 & 3.1 & 6.0 & 8.0 & 9.8 & 9.4 & 29.6 \\
\hline 322 & 1.9 & 9.8 & 17.9 & 27.3 & 20.4 & 7.8 & 1.1 & 2.0 & 2.4 & 2.3 & 1.9 & 1.3 & 3.9 \\
\hline 323 & 0.8 & 3.7 & 8.8 & 21.4 & 24.6 & 10.5 & 1.2 & 1.9 & 3.0 & 3.5 & 4.1 & 4.3 & 12.0 \\
\hline 406 & 0.17 & 21.4 & 44.9 & 20. & 11. & 0.9 & 0.9 & 0.1 & 0.1 & 0.0 & 0.0 & 0.0 & (0.5) \\
\hline 409 & 46.8 & 27.3 & 8.8 & 4.0 & 3.1 & 3.3 & 2.5 & 0.9 & 0.6 & 0.4 & 0.3 & 0.4 & 1.6 \\
\hline 419 & 25.1 & 41.2 & 12.1 & 10.7 & 8.7 & 0.85 & 0.85 & 0.1 & 0.1 & 0.0 & 0.0 & 0.0 & $(0.3)$ \\
\hline 420 & 6.0 & 30.5 & 35.0 & 19.5 & 6.8 & 0.8 & 0.8 & 0.1 & 0.1 & 0.0 & 0.0 & 0.0 & (0.6) \\
\hline
\end{tabular}

Limits are given in micrometers.

washing procedure. The carbonate- and salt-free sample was then transferred to a beaker, and organic matter was destroyed by treatment with $\mathrm{H}_{2} \mathrm{O}_{2}$ and dispersed with $25 \mathrm{ml}$ of Na-pyrophosphate. Stirring and ultrasonication followed. Clays were isolated by sedimentation after removal of the sand fraction by wet sieving. After being mounted on warm ceramic tiles, the clays were $\mathrm{X}$ rayed three times, after being air-dried, ethylene-glycolated and heat-treated $\left(550^{\circ} \mathrm{C}\right)$. The samples were $\mathrm{X}$ rayed at $2^{\circ}(2 \theta) / \mathrm{min}$, using $\mathrm{Cu}$ radiation and a Ni filter. Quantitative estimates were made by using the glycolated (001) peaks after identification according to Carroll [1970] (Table 4).

For four samples (109a, b, 110, 111), exchangeable cations and cation exchange capacity were determined (Table 5). Determinations were made of both $\mathrm{NH}_{4} \mathrm{OAc}$-extractable cations and water soluble cations extracted from saturated pastes; exchangeable cations were calculated as the difference between these two. Cation exchange capacity was determined by the ammonium saturation method [Chapman, 1965].
Hardness of crusts was determined in the laboratory as the modulus of rupture

$$
M=\frac{3 \cdot F \cdot \text { length }}{2 \cdot \text { width } \cdot(\text { thick })^{2}}
$$

where $M$ is modulus of rupture in bars, $F$ is impressed force at which the briquet breaks, 'length' is length between the knife edge supports of the briquet, 'width' is width of the briquet, 'thick' is thickness of the briquet.

The determination used the method described by Richards [1953]. We supplemented field modulus of rupture data with laboratory modulus of rupture data because we were successful in determining field modulus of rupture for only 11 soils. These values were determined after cutting a field crust into dimensions specified by Richards [1953] after transporting it to the laboratory. In many cases, sufficiently large crust pieces did not exist, and in others the crust pieces were broken in attempting to cut appropriately sized briquets in the laboratory. The modulus of rupture was deter- 
TABLE 3. Other Components of Test Soils

\begin{tabular}{|c|c|c|c|c|c|c|c|c|c|}
\hline \multirow[b]{2}{*}{ ID } & \multirow{2}{*}{$\begin{array}{c}\text { Soil } \\
\text { Moisture }\end{array}$} & \multicolumn{3}{|c|}{ Percentages } & \multirow[b]{2}{*}{$p \mathrm{H}$} & \multirow{2}{*}{$\begin{array}{c}\text { Wilt } \\
\text { Moist }\end{array}$} & \multicolumn{3}{|c|}{ Percentage } \\
\hline & & Solubl & Crbnat & Orgnk & & & Cobbl & Pebl & Grnul \\
\hline 101 & 14.5 & 26.26 & 2.1 & 0.07 & 8.1 & 6.7 & 0.0 & 0.0 & 0.01 \\
\hline 102 & 1.66 & 38.6 & 11.8 & & 9.5 & & 0. & 0.11 & 0.04 \\
\hline 103 & 6.41 & 34.1 & 31.1 & & 9.9 & & 0. & 0. & 0. \\
\hline 104 & 1.39 & 30.4 & 10.2 & & 9.6 & & 0. & 0.03 & 0.01 \\
\hline 105 & 0.49 & 86.3 & 6.0 & 0.35 & 9.9 & & 0. & 0. & 0. \\
\hline 106 & 1.98 & 22.9 & 9.3 & & 9.9 & & 0. & 0.72 & 0.28 \\
\hline 107 & 2.70 & 72.3 & 4.6 & & 9.4 & & 0. & 0. & 0. \\
\hline 108 & 3.18 & 46.4 & 5.0 & & 9.4 & & 0. & 0. & 0. \\
\hline $109 a$ & 5.09 & 11.5 & 5.2 & & 8.7 & & 0. & 0.02 & 0.02 \\
\hline $109 b$ & 2.46 & 41.4 & 3.6 & & 8.4 & & 0. & 0.05 & 0.12 \\
\hline 110 & 4.84 & 24.6 & 4.3 & & 8.5 & & 0. & 0.01 & 0.06 \\
\hline 111 & 3.58 & 0.90 & 4.9 & & 8.8 & & 0. & 0. & 0.02 \\
\hline 112 & 0.41 & 13.0 & 8.9 & 0.32 & 9.9 & & 0. & 0.3 & 0.5 \\
\hline 113 & 1.08 & 23.2 & 16.7 & & 9.9 & & 0. & 0. & 0. \\
\hline 301 & 2.6 & 0.35 & 5.6 & 1.58 & 8.2 & 32.4 & 0. & 0. & 0. \\
\hline 302 & 2.7 & 0.63 & 8.0 & 1.51 & 8.0 & 35.1 & 0. & 0. & 0. \\
\hline 303 & 1.6 & 1.27 & 4.6 & 1.40 & 7.9 & 11.6 & 0. & 0.0 & 0.0 \\
\hline $304 a$ & 1.8 & 1.49 & 8.3 & 1.87 & 7.7 & 12. & 0. & 0.02 & 0.13 \\
\hline $304 b$ & 1.8 & 0.50 & 6.8 & .17 & 7.8 & 7.5 & 0. & 0.1 & 0.3 \\
\hline $305 a$ & 8.0 & 0.09 & 1.9 & 2.66 & 7.5 & 39.9 & 0. & 0. & 0. \\
\hline $305 b$ & 8.0 & 0.04 & 0.6 & 2.96 & 7.5 & 26.3 & 0. & 0. & 0. \\
\hline 306 & 2.2 & 0.24 & 18.8 & .33 & 9.8 & 18.2 & 0. & 0. & 0. \\
\hline 307 & 0.7 & 0.04 & .8 & .78 & 9.0 & 4.6 & 0. & 0.3 & 0.4 \\
\hline 308 & 3.0 & 2.11 & 2.8 & .39 & 9.0 & 19.6 & 0. & 0. & 0. \\
\hline 309 & 1.0 & 0.07 & 1.6 & .87 & 8.8 & 6.4 & 0. & 0.00 & 0.05 \\
\hline 310 & 3.3 & 3.02 & 6.4 & 1.08 & 8.4 & 25.9 & 0. & 0.06 & 0.10 \\
\hline 311 & 9.2 & 22.17 & 2.7 & .58 & 8.3 & 16.7 & 0 . & 0. & 0.01 \\
\hline 312 & 2.1 & 0.29 & 4.3 & 1.31 & 9.1 & 18.2 & 0. & 0. & 0. \\
\hline 313 & 3.2 & 3.36 & 14.0 & .30 & 8.2 & 18.6 & 0. & 0.01 & 0.01 \\
\hline 314 & 2.5 & 0.27 & 13.9 & .44 & 8.7 & 16.5 & 0. & 0.01 & 0.01 \\
\hline $315 a$ & 4.5 & 0.04 & 9.5 & .67 & 7.9 & 8.8 & 0. & 0.23 & 0.02 \\
\hline $315 \mathrm{~b}$ & 4.5 & 0.04 & 9.7 & .61 & 8.2 & 11.5 & 0. & 0.5 & 0.04 \\
\hline 316 & 0.48 & 2.4 & 5.0 & & 9.9 & & 0. & 0.03 & 0.26 \\
\hline 317 & 4.52 & 0.35 & 5.2 & & 9.2 & & 0. & 0. & 0. \\
\hline 318 & 3.97 & 0.26 & 5.1 & & 8.9 & & 0. & 0. & 0. \\
\hline 319 & 1.58 & 0.14 & 1.9 & & 9.3 & & 0 . & 0. & 0. \\
\hline 320 & 1.79 & 0.13 & 0. & 4.09 & 7.7 & & 0. & 0.14 & 0.08 \\
\hline 321 & 2.25 & 0.36 & 2.4 & 0. & 9.5 & 17.6 & 0. & 0.03 & 0.13 \\
\hline 322 & 0.22 & 0.27 & 1.2 & 1.65 & 8.3 & 3.1 & 0. & 0. & 0.06 \\
\hline 323 & 0.58 & 1.17 & 1.9 & 2.22 & 8.6 & 6.9 & 0. & 0. & 0.2 \\
\hline 406 & 0.1 & 0.04 & 0. & & 7.7 & & 0. & 0.01 & 0.02 \\
\hline 409 & 0.3 & 0.06 & 0. & & 7.8 & & 0. & 7.5 & 19.4 \\
\hline 419 & 0.23 & 0.43 & 3.0 & & 9.9 & & 0. & 0.03 & 0.28 \\
\hline 420 & 0.06 & 0.05 & 0. & & 8.1 & & 0. & 0. & 0.02 \\
\hline
\end{tabular}

Symbols: Solubl = water soluble material, Crbnat $=$ calcium carbonate, Orgnk $=$ organic material Wilt Moist $=$ soil moisture at -15 bars, Cobbl $=$ cobble, Pebl $=$ pebble, $\mathrm{Gmul}=$ granule.

mined for laboratory-prepared soil crusts by the method of Richards [1953]. In this preparation, the soil sample is passed through a 1-mm sieve, sprinkled into a briquet form by a nonselective procedure and wetted from beneath through blotter paper for 1 hour, and then dried in a forceddraft oven at $50^{\circ} \mathrm{C}$. The briquets formed in this way were compositionally unaltered soil $(A)$, soil from which watersoluble material had been removed $(B)$, soil from which calcium carbonate and water soluble material had been removed $(C)$, and soil from which organic material, water soluble material, and calcium carbonate had been removed $(D)$. The components were removed as above because $\mathrm{CaCO}_{3}$ was removed by treatment with acid which had to be subsequently washed. The washing also removed water soluble material. Organic material was removed by $\mathrm{H}_{2} \mathrm{O}_{2}$ treatment followed by a wash which was better accomplished on $\mathrm{CaCO}_{3}$ free soil. We denote modulus of rupture of field samples by $M(F)$ and modulus of rupture of preparations $A, B, C$, and $D$ by $M(A), M(B), M(C)$, and $M(D)$.
Table 6 lists the threshold velocities for the test soils in undisturbed and disturbed condition along with the roughness height $z_{0}$ defined in equation (1). In general, when threshold velocity could not be reached, $z_{0}$ was not measured. Thickness of soil crust is also listed.

The coarse-aggregate size distribution was determined for each sample by dry sieving. The soil samples were carefully transported to our laboratory to avoid breakage of aggregates. From the size distribution the maxima or modes were obtained for each test (Table 6). These modes represented the size of loose particles available to erode for the given soil. Some qualitative descriptors of the crust surface are also listed in Table 6.

\section{Aerodynamic Roughness Heights}

In general, the values of aerodynamic roughness height, $z_{0}$, reflected the visual appearance of roughness, the details of which were quantified by Lettau [1969]. Rough, lumpy, highly cracked clay crusts and crusts covered with salt 
TABLE 4. Clay and Salt Mineralogy for Tested Soils

\begin{tabular}{|c|c|c|c|c|c|c|c|c|c|c|c|}
\hline \multirow[b]{2}{*}{ ID } & \multicolumn{5}{|c|}{ Clay Mineralogy* } & \multicolumn{6}{|c|}{ Salt Mineralogy* } \\
\hline & SM & MI & $\mathbf{K A}$ & $\mathbf{C L}$ & VR & $\mathbf{C A}$ & HA & $\mathbf{B X}$ & AN & SL & SN \\
\hline$\overline{101}$ & 3 & 4 & 2 & & 1 & 1 & 9 & & & & \\
\hline 102 & 1 & 6 & 1 & 2 & & i & 7 & & 1 & 1 & \\
\hline 103 & 1 & 1 & 1 & 1 & 1 & 2 & 5 & & 3 & & \\
\hline 104 & 1 & 7 & & 2 & & 2 & 8 & & & & \\
\hline 105 & 2 & 5 & & 2 & 1 & & 10 & & & & \\
\hline 106 & 2 & 6 & & 2 & & & 4 & 1 & 2 & 1 & 2 \\
\hline 107 & 5 & 3 & & 2 & & & 10 & & & & \\
\hline 108 & 4 & 4 & & 2 & & & 10 & & & & \\
\hline $109 a$ & 6 & 3 & & 1 & & & 6 & 1 & 1 & & 2 \\
\hline $109 \mathrm{~b}$ & 5 & 4 & & i & & 9 & & & & & 1 \\
\hline 110 & 7 & 3 & & & & & 8 & & & & 2 \\
\hline 111 & 5 & 2 & & 3 & & & & & & & tr \\
\hline 112 & 4 & 4 & 2 & & & 8 & 2 & & & & \\
\hline 113 & 4 & 3 & 1 & 1 & 1 & 4 & 3 & & & 3 & \\
\hline 301 & 3 & 4 & 2 & 1 & & & & & & & \\
\hline 302 & 3 & 4 & 2 & 1 & & & & & & & \\
\hline 303 & 3 & 4 & 2 & 1 & & & & & & & \\
\hline 304 & 3 & 5 & 2 & & & & & & & & \\
\hline $305 a$ & 1 & 6 & 3 & & & & & & & & \\
\hline $305 b$ & 1 & 5 & 4 & & & & & & & & \\
\hline 306 & i & 7 & 2 & & & & & & & & \\
\hline 307 & 2 & 5 & 3 & & & & & & & & \\
\hline 308 & 1 & 2 & 5 & 2 & & & & & & & \\
\hline 309 & 1 & 2 & 5 & 2 & & & & & & & \\
\hline 310 & 4 & 4 & 1 & 1 & & & & & & & \\
\hline 311 & 5 & 3 & 2 & & & & 10 & & & & \\
\hline 312 & 6 & 3 & $\overline{1}$ & & & & & & & & \\
\hline 313 & 2 & 5 & 2 & & 1 & & & & & & \\
\hline 314 & 3 & 4 & 2 & 1 & & & & & & & \\
\hline $315 \mathrm{a}$ & 1 & 3 & 5 & 1 & & & & & & & \\
\hline $315 b$ & 1 & 4 & 4 & 1 & & & & & & & \\
\hline 316 & 0 & 0 & o & 0 & $\mathbf{0}$ & 1 & 3 & 2 & 4 & & \\
\hline 317 & 6 & 3 & & 1 & & 0 & 0 & 0 & 0 & 0 & 0 \\
\hline 318 & 6 & 2 & & 2 & & 0 & 0 & 0 & 0 & 0 & 0 \\
\hline 319 & 5 & 3 & & 2 & & 4 & & & 6 & & \\
\hline 320 & 5 & 1 & & 4 & & & & & & & \\
\hline 321 & 1 & 7 & & 2 & & & & & & & \\
\hline 322 & 3 & 3 & & 4 & & & & & & & \\
\hline 323 & 1 & 3 & 4 & 2 & & & & & & & \\
\hline 406 & & & & & & & & & & & \\
\hline 409 & 1 & 5 & 2 & & 2 & & & & & & \\
\hline 419 & 0 & 0 & 0 & 0 & 0 & 2 & 2 & & 4 & & \\
\hline 420 & 2 & 4 & & 4 & & 0 & 0 & 0 & 0 & 0 & 0 \\
\hline
\end{tabular}

*SM = smectite, $\mathrm{MI}=$ mica, $\mathrm{KA}=$ kaolinite, $\mathrm{CL}=$ chlorite, $\mathrm{VR}=$ vermiculite, $\mathrm{CA}=$ calcite, $\mathrm{HA}$ $=$ Halite, $\mathrm{BX}=$ borax, $\mathrm{AN}=$ anhydrite, $\mathrm{SL}=$ sylvite, $\mathrm{SN}=$ soda niter; anhydrite identifications are tentative; thenardite may be present in a few samples. Quantities are tenths.

spicules had $z_{0}$ values ranging from 0.1 to $0.3 \mathrm{~cm}$. These soils were located at Lake Danby, Silver Lake, Searles Lake, and near Craig, Colorado. (Soils 103, 107, 108, 301, 302, 317, 318, 319 , and 320.) There were three extremely small $z_{0}$ values $\left(z_{0}<0.001 \mathrm{~cm}\right)$ corresponding to flat and almost polished clay surfaces formed by sedimentation of fine clay particles in water followed by evaporation (soils 314 and 111 at Soggy Lake and Soda Lake) and one densely packed fine sand crust (soil 420). The remaining $z_{0}$ values ranged from 0.001 to 0.1 $\mathrm{cm}$. They increase from those of fine sand and smooth clay crusted soils to gravelly sand soils and rough clay crusted soils.

The disturbance by a truck tire did not have the effect of bringing up rougher material to the surface, but rather of smoothing the surface by crushing and mixing of aggregated soils and surface deposits. Thus, except for two exceptions,

TABLE 5. Exchangeable Cations and Cation Exchange Capacities for Selected Soils

\begin{tabular}{|c|c|c|c|c|c|c|c|c|c|c|c|c|c|c|}
\hline \multirow[b]{2}{*}{ Site } & \multicolumn{4}{|c|}{$\begin{array}{l}\mathrm{NH}_{4} \mathrm{OAc}-\text { Extractable Cations } \\
(\mathrm{meq} / 100 \mathrm{~g})\end{array}$} & \multicolumn{4}{|c|}{$\begin{array}{l}\text { Water-Soluble Cations } \\
\text { (meq/100 g) }\end{array}$} & \multicolumn{6}{|c|}{$\begin{array}{l}\text { 'Exchangeable' Cations } \\
\text { (meq/100 g) }\end{array}$} \\
\hline & $\overline{\mathrm{Ca}^{++}}$ & $\mathrm{Mg}^{++}$ & $\mathrm{Na}^{+}$ & $\overline{\mathrm{K}^{+}}$ & $\mathrm{Ca}^{++}$ & $\mathrm{Mg}^{++}$ & $\mathrm{Na}^{+}$ & $\overline{\mathbf{K}^{+}}$ & $\overline{\mathrm{Ca}^{++}}$ & $\mathrm{Mg}^{++}$ & $\mathrm{Na}^{+}$ & $\overline{\mathbf{K}^{+}}$ & CEC $^{1}$ & $\overline{\text { ESP }^{2}}$ \\
\hline $109 a$ & 48.9 & 1.4 & 362.9 & 1.3 & 1.0 & 0.1 & 240.1 & 0.2 & 47.9 & 1.3 & 122.8 & 1.1 & 29.3 & $100 ?$ \\
\hline $109 \mathrm{~b}$ & 41.0 & 1.1 & 737.7 & 1.3 & 0.6 & 0.0 & 187.5 & 0.2 & 40.4 & 1.1 & 550.2 & 1.1 & 21.5 & $100 ?$ \\
\hline 110 & 39.0 & 1.2 & 382.3 & 1.1 & 1.3 & 0.1 & 267.3 & 0.2 & 37.7 & 1.1 & 115.0 & 0.9 & 30.4 & $100 ?$ \\
\hline 111 & 41.9 & 1.6 & 33.8 & 1.2 & 1.8 & 0.1 & 15.2 & 0.0 & 40.1 & 1.5 & 18.6 & 1.2 & 27.3 & 68.1 \\
\hline
\end{tabular}

${ }^{1}$ Cation exchange capacity, in meq/100 g.

${ }^{2}$ Exchangeable sodium percentage. 
TABLE 6. Threshold Velocity Experimental Data

\begin{tabular}{|c|c|c|c|c|c|c|c|c|}
\hline \multirow[b]{2}{*}{ ID } & \multicolumn{4}{|c|}{ Undisturbed } & \multicolumn{3}{|c|}{ Disturbed } & \multirow[b]{2}{*}{ Soil Crust Condition } \\
\hline & $U_{* \text { th }}$ & $z_{0}$ & Thick & Mode & $U_{n_{\text {th }}}$ & $z_{0}$ & Mode & \\
\hline 101 & 999. & & 0.60 & 9.9999 & 999. & & 9.9999 & flat crust-moist under \\
\hline 102 & 999. & & 1.91 & 4.8000 & 999. & & 0.1500 & rough crust with spicules \\
\hline 103 & 69. & 0.115 & 1.91 & ; 4.8000 & 38. & 0.005 & 0.0187 & sand with salt crusting \\
\hline 104 & 999. & & 1.27 & 9.9999 & 999. & & 9.0000 & soil-flat crust \\
\hline 105 & 999. & & 0.64 & 9.9999 & 999. & & 9.0000 & soil-flat salt \\
\hline 106 & & & 1.27 & & 262. & 0.0274 & 1.0000 & disturbed-broken \\
\hline 107 & 69. & 0.121 & 0.33 & 0.3000 & & & & salt fluff-wave produced \\
\hline 108 & 69. & 0.121 & 0.15 & 0.0187 & & & & salt fluff-wave produced \\
\hline $109 \mathrm{a}$ & 999. & & 0.64 & 9.9999 & & & & domed crust (blister) \\
\hline $109 \mathrm{~b}$ & 999. & & 0.64 & 9.9999 & & & & domed crust (blister) \\
\hline 110 & 23. & 0.0012 & 0.00 & 0.0187 & & & & loose beneath dome \\
\hline 111 & 999. & & 1.91 & 4.8000 & 21. & 0.0002 & 0.0100 & flat crust \\
\hline 112 & & & & & 20. & 0.003 & 0.0187 & loose wind deposit \\
\hline 301 & 999. & & 1.30 & 3.5000 & 182. & 0.19 & 1.5000 & cracked, curled \\
\hline 302 & 999. & & 1.30 & 1.5000 & 158. & 0.24 & 0.1500 & cracked, curled \\
\hline 303 & 999. & & 1.30 & 3.5000 & 40. & 0.006 & 0.0100 & rough, cracked, soft \\
\hline $304 a$ & 265. & 0.006 & 0.50 & 1.5000 & 29. & 0.0057 & 0.0750 & thin, weak, cracked \\
\hline $304 b$ & 265. & 0.007 & 0.50 & 1.5000 & 29. & 0.0057 & 0.0750 & thin, weak, cracked \\
\hline $305 a$ & 204. & 0.068 & 0.00 & 1.5000 & & & & pellet-sized detached \\
\hline $305 \mathrm{~b}$ & 35. & 0.002 & 0.00 & 0.0750 & & & & pellet-sized detached \\
\hline 306 & 999. & & 3.80 & 9.9999 & 36. & 0.016 & 0.0275 & flat, not cracked \\
\hline 307 & & & & & 35. & 0.01 & 0.0375 & disturbed, powdery \\
\hline 308 & 999. & & 2.50 & 9.9999 & 35. & 0.01 & 0.0175 & flat, no cracks \\
\hline 309 & 999. & & 1.90 & 1.5000 & 27. & 0.005 & 0.0750 & flat, no cracks \\
\hline 310 & 999. & & 0.60 & 1.5000 & 51. & 0.016 & 0.4850 & curled, cracked \\
\hline 311 & 999. & & 0.60 & 3.5000 & 101. & 0.07 & 0.0375 & curled, cracked \\
\hline 312 & 121. & 0.004 & 0.08 & 0.3000 & 33. & 0.004 & 0.0175 & detached thin curls \\
\hline 313 & 999. & & 1.30 & 3.5000 & 88. & 0.008 & 0.3000 & curled \\
\hline 314 & 999. & & 2.50 & 3.5000 & 19. & 0.0001 & 0.1500 & flat, small cracks \\
\hline $315 a$ & 261. & 0.09 & 0.30 & 3.5000 & 35. & 0.3 & 0.0750 & cracked, flat, thin \\
\hline $315 b$ & 261. & 0.09 & 0.60 & 3.5000 & 35. & 0.3 & 0.750 & cracked, flat, thin \\
\hline 316 & 114. & 0.0313 & 0.64 & 0.0187 & 40. & 0.0035 & 0.0100 & sandy \\
\hline 317 & 411. & 0.25 & 1.41 & 1.2000 & 50. & 0.0124 & 0.6000 & highly cracked \\
\hline 318 & 999. & & 1.41 & 1.2000 & 232. & 0.27 & 0.3000 & cracked, detached peds \\
\hline 319 & 999. & & 1.27 & 4.8000 & 100. & 0.17 & 0.0750 & domed-sandy-no cracks \\
\hline 320 & 290. & 0.18 & 0.60 & 3.5000 & 20. & 0.003 & 0.0750 & thin, weak crust \\
\hline 406 & 40. & 0.014 & 0.60 & 0.1500 & 28. & 0.001 & 0.0750 & very weak crust \\
\hline 409 & 78. & 0.017 & 1.30 & 0.0175 & 72. & 0.016 & 0.0375 & gravel-sand, weak \\
\hline 419 & 67. & 0.0031 & 0.64 & 0.0750 & 49. & 0.0174 & 0.0100 & not homogeneous sand \\
\hline 420 & 37. & 0.0004 & 0.00 & 0.0375 & 38. & 0.0038 & 0.0100 & fine sand \\
\hline
\end{tabular}

Centimeter-gram-seconds units are used.

Symbols: $U_{+\mathrm{h}}$ is threshold friction velocity $(\mathrm{cm} / \mathrm{s}), z_{0}$ is aerodynamic roughness height, thick is crust thickness in $\mathrm{cm}$, mode is the mode of the soil mass size distribution, 999 . means $U_{*_{\mathrm{th}}}$ not reached, 9.9999 in mode means unbroken crust.

aerodynamic roughness heights were roughly the same or smaller following disturbance. Cases when the overall crust structure was virtually unaffected except for loosening of a very thin $(<1 \mathrm{~mm})$ layer of surface material were for soils $111,306,308,312,314$, and 316. When coarse textured surface soils were disturbed, the new surface was often simply mixed but maintained the same or smoother visual roughness (soils 319,406 , and 409). Some soft clay crusts were totally crushed and smoothed so that the surface after crushing had a similar or smoother surface roughness (soils $303,304,309,315,320)$. Some harder clay crusts which were cracked and rough broke into large chunks which had similar or smaller roughness (soils $301,302,310,311,313,317$ ). Soils having roughness due to salt spicules were smoothed by crushing the salt spicules (soils 102, 103). Soil 101 was moist. Only for soils 419 and $\mathbf{4 2 0}$ were coarser grains brought to the surfaces to actually increase $z_{0}$.

\section{Threshold Velocity Versus Soll Properties} Undisturbed Soils

The wind velocities that our portable wind tunnel equipment could develop were not strong enough to erode most undisturbed crusted clay soils. The soils that did erode in undisturbed conditions, however, had certain things in common: (1) the solid surface had loose sand or pellet-sized material present or (2) the soil had a thin (less than $0.7 \mathrm{~cm}$ ) and weak (modulus of rupture less than 0.7 bar) surface crust. For these soils, threshold friction velocity was larger than $250 \mathrm{~cm} \mathrm{~s}^{-1}$ and less than $300 \mathrm{~cm} \mathrm{~s}^{-1}$. Velocities of this high magnitude are rarely found in nature except in intense localized phenomena (e.g., dust devils).

For the case of loose material on the surface, threshold friction velocity was related to the mode of the mass size distribution of the loose material [see Gillette et al., 1980]. Loose material was usually associated with sandy soils with very little clay (samples 103, 316, 406, 409, 419) or clay peels formed after drying of mud on clay soils (312), or cracked clay soil with pellet-sized loose fragments on the surface $(305,317)$, wave-produced salt fluff near a saline water pool $(107,108)$, subsurface soil after a crust had been removed by us (110), or an unconsolidated wind deposition $(112,420)$. The thin, weak crusts, which eroded at $U_{*}>250 \mathrm{~cm} \mathrm{~s}^{-1}$, usually eroded in pieces into which the crust had already cracked before the wind tunnel test. 


\section{Disturbed Soils}

We disturbed soils with the accelerating wheels of a onequarter-ton pickup truck that had mud-snow tires. Thus, our disturbance is restricted to one type, although in the discussion we try to generalize for different disturbances. When $U_{* \text { th }}$ was examined for disturbed soils versus the parameter expressing hardness of the crust (modulus of rupture) it was clear that the vulnerability to disturbance could be separated at modulus of rupture between 1 and 2 bars. For soils having modulus of rupture less than 1 bar, the threshold velocities for wind erosion were less than $45 \mathrm{~cm} \mathrm{~s}^{-1}$, which is a common velocity in the desert. For modulus of rupture greater than 2, however, there was no clear-cut relationship. When disturbed friction velocities were plotted against modulus of rupture times the square of crust thickness a fairly clear relationship was seen. For silt crusts thinner than 1.9 $\mathrm{cm}$, the threshold velocity may be expressed by the regression formula:

$$
\begin{aligned}
U_{* \text { th }}= & 42.9+12.1\left(M \cdot \text { thick}^{2}\right) \\
& \text { for }\left(M \cdot \text { thick }^{2}\right) \leq 20{\text { bar } \mathrm{cm}^{2}}^{2} \\
r^{2}= & 0.53 \\
\sigma_{\text {res }}= & 51.7 \\
\text { d.f. }= & 17
\end{aligned}
$$

$U_{* \text { th }}$ not reached by our equipment for

$$
\left(M \cdot \text { thick }^{2}\right)>35 \text { bar } \mathrm{cm}^{2}
$$

where $r^{2}$ is the correlation coefficient squared and d.f. is the number of degrees of freedom.

Not used in the above analysis was the wet soil 101. Field modulus of rupture, $M(F)$, was used when available; otherwise $M(A)$ was used. Soils having no crust before disturbance (thick $=0$ ) were not used in the analysis since the disturbance acted only to redistribute loose material, not to break an existing crust. These soils were samples 420 and 112 , both of which were most likely recently deposited by wind. All of the crusts for which thick $<1.9 \mathrm{~cm}$ and $M$. thick ${ }^{2}<20$ bar $\mathrm{cm}^{2}$ were pulverized by our disturbance; for $M \cdot$ thick $^{2}>40$ bar $\mathrm{cm}$ the crust, if broken at all, was in large enough pieces to resist wind erosion. The relationship of (3) is probably due to the influence of hardness and thickness on the size of pieces of the pulverized crust. The harder and thicker the crust, the larger the mode of the aggregate size distribution. The mode was shown by Gillette et al. [1980] to have strong correlation with threshold wind velocity. Indeed the mode of the aggregate size distribution when regressed against $\left(M \cdot\right.$ thick $\left.^{2}\right)$ was expressed for thick $<1.9 \mathrm{~cm}$.

$$
\begin{aligned}
\text { mode }= & 324+705\left(M \cdot \text { thick }^{2}\right) \\
& \text { for }\left(M \cdot \text { thick }^{2}\right)<20 \mathrm{bar} \cdot \mathrm{cm}^{2} \\
r^{2}= & 0.64 \\
\sigma_{\text {res }}= & 2424 \mu \mathrm{m} \\
\text { d.f. }= & 17
\end{aligned}
$$$$
\text { crust intact for }\left(M \cdot \text { thick }^{2}\right)>40
$$

For crusts thicker than $1.9 \mathrm{~cm}$ and $M>2$ bars, the disturbance simply loosened a very small layer of soil material at the top of the soil crust which was erodible at $U_{*}$ $<50 \mathrm{~cm} \mathrm{~s}^{-1}$. When this small amount of material (on the order of a few grams per $\mathrm{m}^{2}$ ) was eroded away by the wind, the underlying crust was not erodible and appears not to have been affected by the disturbance. Although the amount of loose material produced was not measured, it as our observation that more loose material was produced at sites having lower moduli of rupture.

\section{Relationship of Modulus of Rupture to SoIL CoMPOSITION}

Since the threshold friction velocities of both undisturbed and disturbed soil crusts are related to modulus of rupture of the soil, the relation of modulus of rupture to composition of the soil was sought so that threshold velocities could be understood as related to fundamental soil constituents. Four constituents are clay, calcium carbonate, water soluble material (soluble salts) and organic material. The effect on modulus of rupture of these four soil constituents may be written:

$$
\begin{aligned}
d M=\frac{\partial M}{\partial \text { salt }} \Delta \text { salt } & +\frac{\partial M}{\partial \mathrm{CaCO}_{3}} \Delta \mathrm{CaCO}_{3} \\
& +\frac{\partial M}{\partial \text { clay }} \Delta \text { clay }+\frac{\partial M}{\text { dorganic }} \Delta \text { organic }
\end{aligned}
$$

where $M$ is modulus of rupture, salt is percentage of mass of water soluble matter, $\mathrm{CaCO}_{3}$ is percentage by mass of calcium carbonate, clay is percentage, by mass, of mineral particles (not calcium carbonate or water-soluble material) smaller than $4 \mu \mathrm{m}$ diameter, organic is percentage, by mass, of organic material. In determining the values of

$$
\frac{\partial M}{\partial \text { salt }}, \frac{\partial M}{\partial \mathrm{CaCO}_{3}}, \frac{\partial M}{\partial \text { clay }} \text {, and } \frac{\partial M}{\partial \text { organic }}
$$

the following assumptions were made:

1. The effects of water-soluble material and calcium carbonate are mutually independent. That is, they do not interact. This assumption was borne out in an experiment in which nonsaline, noncarbonaceous mineral soils were mixed with quantities of $\mathrm{NaCl}$ and $\mathrm{CaCO}_{3}$ in the proportions shown in Table 7.

The moduli of rupture for four sets of mixtures in which the original soils were sand with little clay (420), silty soil (307), or two clay-textured soils (305) are shown in Figure 1. Within the rough limits of the measurements, no obvious interaction of water-soluble material and the fine powdered $\mathrm{CaCO}_{3}$ was seen.

2. The effects of organic additives are independent of other effects. Indeed, since the effects of organic additives were found to be nonsignificant for our desert soil samples, this assumption seemed to be reasonable.

The method of computation of the individual partial derivatives was as follows:

$$
\left.\frac{\partial M}{\partial \mathrm{salt}}\right|^{\begin{array}{l}
\Delta \text { salt } \\
\text { constant clay, } \\
\mathrm{CO}_{3}, \text { organic }
\end{array}}=M(A)-M(B)
$$

where $M(A)$ is the modulus of rupture for briquet treatment A.

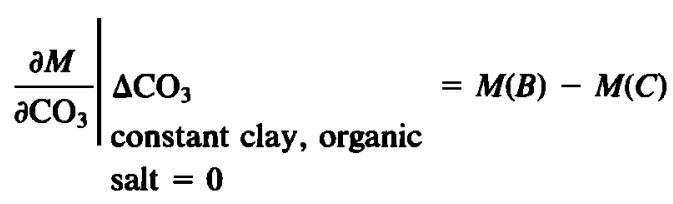


TABLE 7. Percentage Composition of Experimental Soils

\begin{tabular}{cccc}
\hline & Original & $\mathrm{NaCl}$ & $\mathrm{CaCO}_{3}$ \\
\hline $\boldsymbol{A}$ & Soil & 0 & 0 \\
$\boldsymbol{X}$ & $100 \%$ & $25 \%$ & 0 \\
$\boldsymbol{Z}$ & $75 \%$ & 0 & $25 \%$ \\
& $75 \%$ & $25 \%$ & $25 \%$ \\
\hline
\end{tabular}

$$
\begin{aligned}
& \left.\frac{\partial M}{\text { dorganic }}\right|_{\begin{array}{l}
\text { constant clay, } \\
\text { salt }=0, \mathrm{CO}_{3}=0
\end{array}} \Delta \text { organic }=M(C)-M(D) \\
& M(\text { clay }) \mid \begin{array}{l}
\text { salt }=0, \mathrm{CO}_{3}=0, \\
\text { organic }=0
\end{array}=M(D)
\end{aligned}
$$

Clay was further subdivided into four mineralogical groups and a limited number of samples was examined for the effect of exchangeable sodium.

Table 8 lists the modulus of rupture data for field crusts and laboratory treatments $A, B, C$, and $D$. Also given in the table are computed standard deviations of the modulus of rupture determination and number of determinations for each mean. Differences between modulus of rupture determinations were accepted only when the difference was greater than $2\left(\sigma_{1}^{2}+\sigma_{2}^{2}\right)^{1 / 2}$ where $\sigma_{1}$ and $\sigma_{2}$ are the standard deviations for the two moduli of rupture.

For those cases where the quantity of a specific soil component was negligible in the field sample, we did not remove that component and no briquets were made for that sample. For samples 107 and 108, insufficient material existed for briquets other than for treatment $\boldsymbol{A}$.

\section{Difference in Modulus of Rupture Between Field Crust Samples and Reconstituted Laboratory Briquets}

Modulus of rupture was determined on a limited number of cases in which suitable sized pieces of the natural crust could be cut into the size of the laboratory briquet. The results for the field and laboratory crusts are given in Table 8. In general most samples had $|M(F)-M(A)|$ within $2 \sqrt{\sigma_{F}^{2}+\sigma_{A}^{2}}$. Soils 104 and 105 were extremely high in salt content (salt $>20 \%$ ). It was noted, however, that the $A$ briquets had the appearance of a crust formed from cemented small salt chunks that passed through the 1-mm sieve. The field crusts, however, were almost monolithic. It is probable that the significant difference between field and laboratory moduli of rupture was due to differences in formation of the crusts. For the case of the field crust the soil was probably waterlogged long enough to dissolve the salt completely, and evaporation was slow enough to allow the mixture to harden slowly. The laboratory soil had only 1 hour to dissolve and about $\mathbf{7 2}$ hours to dry before testing. The laboratory crust of soil 111 was much more compact than was the field crust, which made $M(A)>M(F)$. The field crust is in general formed in a different way from the laboratory crust, but six of the nine samples show agreement within two standard deviations of the difference.

Being aware that differences in formation can produce different values for modulus of rupture, we nonetheless used laboratory modulus of rupture for analysis of soil composition effects. This was done for the sake of consistency since all of the laboratory crusts for the composition tests were produced in the same way. Field modulus of rupture was used in conjunction with field $U_{* \text { th }}$ when it was available.

\section{The Effect of Clay on Modulus of Rupture}

The moduli of rupture for soils in which water-soluble material, calcium carbonate, and organic material were removed were regressed against percentage of clay (those mineral soil particles smaller than $4 \mu \mathrm{m}$ ) for the four clay mineral groupings shown in Table 9. Three of the four groups were shown by the 'extra sum of squares principle' [Draper and Smith, 1966, section 2.7] to have identical regressions at the 5\% level. Those groups were Mica-Smectite, KaoliniteChlorite, and Smectite excluding samples 109a, b, 110 and 111. The equation for this regression is

$$
\begin{aligned}
M & =-0.63+0.08 \cdot(\text { clay }) \\
r^{2} & =0.782 \\
\sigma_{\text {res }} & =1.16 \\
\text { d.f. } & =26
\end{aligned}
$$

For the Mica group the regression equation was

$$
\begin{aligned}
M & =0.049+0.0076 \cdot(\text { clay }) \\
r^{2} & =0.63 \\
\sigma_{\text {res }} & =0.2 \\
\text { d.f. } & =14
\end{aligned}
$$

Soil samples having less than $3 \%$ clay were shared by both groupings.

Compared with the other groups the Mica group showed a much smaller crustal strength for a given percentage of clay. Possibly this is due to a lower specific surface for mica. The increase of modulus of rupture with clay content is consistent with the work of Kemper et al. [1975] who found a correlation coefficient of 0.95 between modulus of rupture

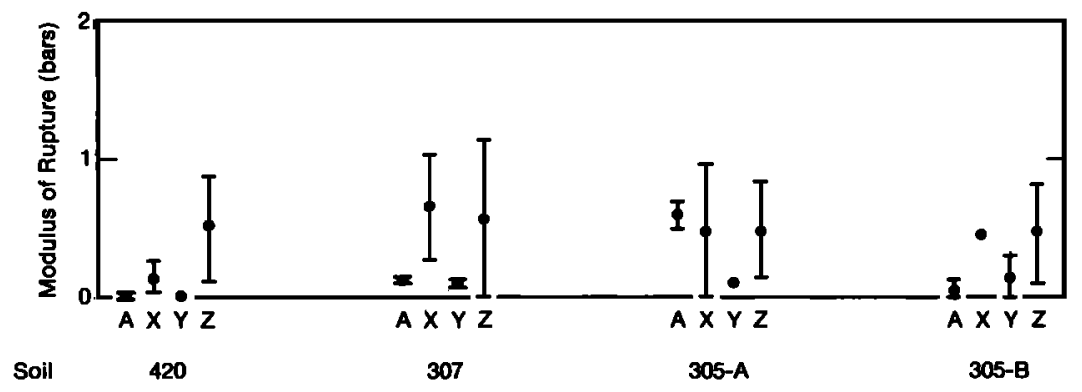

Fig. 1. Modulus of rupture for four soil samples with artificially added salt and calcium carbonate. 
TABLE 8. Modulus of Rupture of Test Soils

\begin{tabular}{|c|c|c|c|c|c|c|c|c|c|c|c|c|c|c|c|}
\hline \multirow[b]{3}{*}{ ID } & \multicolumn{15}{|c|}{ Modulus of rupture in bars } \\
\hline & \multicolumn{3}{|c|}{ Field } & \multicolumn{3}{|c|}{ A (Lab) } & \multicolumn{3}{|c|}{$B$ (salt free) } & \multicolumn{3}{|c|}{$\mathrm{C}\left(\mathrm{CO}_{3}\right.$-free $)$} & \multicolumn{3}{|c|}{ D (no organic) } \\
\hline & Mean & Sig & DF & Mean & Sig & $\overline{\mathrm{DF}}$ & Mean & Sig & DF & Mean & Sig & DF & Mean & Sig & DF \\
\hline 101 & 2.79 & & 1 & 4.28 & 0.86 & 5 & 1.65 & 0.45 & 2 & & & & & & \\
\hline 102 & 21.59 & 7.31 & 6 & 10.53 & 6.08 & 3 & 1.45 & 0.19 & 2 & 0.44 & 0.06 & 2 & & & \\
\hline 103 & 2.77 & 0.41 & 4 & 4.13 & 0.62 & 2 & 0.58 & 0.24 & 2 & 0. & 0.0 & 2 & & & \\
\hline 104 & 80.8 & 20.2 & $j$ & 13.44 & 1.54 & 2 & 0.97 & 0.40 & 2 & 0.20 & 0.01 & 2 & & & \\
\hline 105 & 107.3 & 10.4 & 5 & 11.59 & 2.82 & 5 & 3.04 & 0.16 & 2 & 1.37 & 0.18 & 2 & 0.8 & 0.23 & 4 \\
\hline 106 & & & & 4.91 & 3.1 & 4 & 0.52 & 0.29 & 2 & 0.60 & 0.01 & 2 & & & \\
\hline 107 & 0. & & 1 & & & & & & & & & & & & \\
\hline 108 & 0. & & 1 & 2.35 & 0.24 & 2 & & & & & & & & & \\
\hline $109 a$ & 13.6 & 7.3 & 7 & 12.48 & 1.53 & 2 & 23.14 & 2.96 & 2 & & & & & & \\
\hline $109 \mathrm{~b}$ & 13.6 & 7.3 & 7 & 9.21 & 2.87 & 3 & 18.56 & 1.53 & 2 & & & & & & \\
\hline 110 & & & & 9.63 & 2.60 & 4 & 17.85 & 0.45 & 2 & & & & & & \\
\hline 111 & 1.76 & 0.68 & 5 & 4.57 & 0.51 & 2 & 14.16 & 1.17 & 2 & & & & & & \\
\hline 112 & & & & 1.28 & 0.06 & 3 & 0.61 & 0.09 & 2 & 0.57 & 0.06 & 2 & 0.15 & 0.05 & 2 \\
\hline 113 & & & & 1.46 & 0.15 & 2 & 0.89 & 0.06 & 2 & 0.73 & 0.08 & 2 & 0.41 & 0.08 & 2 \\
\hline 301 & & & & 8.11 & 1.79 & 2 & 10.87 & 3.31 & 5 & 5.95 & 0.35 & 2 & 6.22 & 0.67 & 3 \\
\hline 302 & & & & 4.89 & 1.1 & 2 & 8.77 & 0.48 & 2 & 5.95 & 0.6 & 2 & 6.26 & 0.0 & 2 \\
\hline 303 & & & & 0.31 & 0.15 & 3 & 0.29 & 0.03 & 2 & 0.07 & 0.04 & 2 & 0.38 & 0.00 & 2 \\
\hline $304 a$ & & & & 0.66 & 0.18 & 2 & 2.44 & 0.36 & 1 & & & & & & \\
\hline $304 b$ & & & & 0.36 & 0.02 & 2 & 1.18 & 0.03 & 2 & & & & & & \\
\hline $305 a$ & & & & 0.62 & 0.04 & 2 & 0.72 & 0.30 & 2 & 0.49 & 0.04 & 2 & 0.51 & 0.31 & 2 \\
\hline $305 \mathrm{~b}$ & & & & 0.05 & 0.03 & 2 & 0.13 & 0.02 & 2 & 0. & 0.0 & 2 & 0.05 & 0.05 & 2 \\
\hline 306 & & & & 2.08 & 0.57 & 4 & & & & 0.41 & 0.4 & 4 & & & \\
\hline 307 & & & & 0.13 & 0.01 & 3 & 0.08 & 0.00 & 2 & & & & & & \\
\hline 308 & & & & 7.55 & 2.40 & 2 & 5.82 & 0.17 & 3 & & & & & & \\
\hline 309 & & & & 0.79 & 0.08 & 4 & & & & 0.67 & 0.02 & 3 & & & \\
\hline 310 & & & & 4.06 & 0.84 & 4 & 4.63 & 0.15 & 2 & 5.98 & 0.87 & 2 & & & \\
\hline 311 & & & & 6.00 & 1.55 & 2 & 2.90 & 0.18 & 2 & & & & & & \\
\hline 312 & & & & 2.66 & 0.12 & 2 & 1.75 & 0.17 & 2 & & & & & & \\
\hline 313 & & & & 3.71 & 0.05 & 2 & 4.97 & 0.43 & 2 & 0.84 & 0.24 & 2 & & & \\
\hline 314 & & & & 2.72 & 0.29 & 2 & & & & 1.12 & 0.04 & 2 & & & \\
\hline $315 a$ & & & & 0.62 & 0.04 & 2 & 0.83 & 0. & 2 & 0.23 & 0.01 & 2 & & & \\
\hline $315 b$ & & & & 0.19 & 0.01 & 2 & 0.31 & 0.05 & 2 & 0.17 & & 1 & 0.38 & 0.18 & 2 \\
\hline 316 & & & & 0.16 & 0.05 & 2 & 0.04 & 0.02 & 2 & & & & & & \\
\hline 317 & & & & 5.54 & 0.90 & 2 & 7.20 & 1.58 & 2 & & & & & & \\
\hline 318 & & & & 3.97 & 0.31 & 2 & 7.25 & 0.25 & 2 & & & & & & \\
\hline 319 & 2.12 & .70 & & 2.27 & 1.87 & 2 & 1.49 & 0.52 & 2 & & & & & & \\
\hline 320 & & & & 0.04 & 0.04 & 2 & 0.13 & 0.07 & 2 & & & & 0.84 & 0.01 & 2 \\
\hline 321 & & & & 12.37 & 7.95 & 2 & 0.75 & 0.08 & 2 & & & & & & \\
\hline 322 & & & & 0.28 & 0.10 & 4 & 0.47 & 0.18 & 2 & 0.11 & 0.01 & 2 & 0.16 & 0.11 & 2 \\
\hline 323 & & & & 1.58 & 0.60 & 2 & 1.17 & $0: 01$ & 2 & 0.06 & 0.01 & 2 & 0.40 & 0.06 & 2 \\
\hline 406 & & & & 0. & 0.0 & 2 & 0. & & 1 & & & & & & \\
\hline 409 & & & & 0.04 & 0.01 & 2 & 0. & & 1 & & & & & & \\
\hline 419 & & & & 0.03 & & 1 & 0. & 0. & 1 & & & & & & \\
\hline 420 & & & & 0. & 0. & 2 & 0. & 0. & $i$ & & & & & & \\
\hline
\end{tabular}

Symbols: Sig $=$ standard deviation, $\mathrm{DF}=$ number of determinations.

and percentage of clay-sized hydrous mica in synthetic soils. They reported greater variability for natural soils, however.

\section{Effect of Exchangeable Sodium in Clays}

The effect of sodium in the exchange complex of clays has been noted by Brooks et al. [1956] and Kemper et al. [1975] to increase the strength of the crust. Osmotic swelling forces pull water into the diffuse layer of adsorbed sodic ions, keeping clay from aggregating while wet. Upon drying, however, the clays are pulled into a closely oriented configuration which adds strength to the crust. Brooks et al. [1956] presented data suggesting that modulus of rupture is related to the exchangeable sodium percentage for a given cation exchange capacity (C.E.C.) as

$$
M=M(\mathrm{ESP}=0)+(B \cdot \mathrm{ESP})
$$

where $B$ is a constant and ESP is exchangeable sodium percentage (meq/100 g).

The effect of exchangeable sodium would be large only for soils having high clay content with a large cation exchange capacity. Such clays would be in the Smectite group [Buckman and Brady, 1969]. Indeed, four Soda Lake samples $(109 \mathrm{a}, \mathrm{b}, 110,111)$ having apparent large exchangeable sodium concentrations (Table 5) were not included in regression equation (5) and have much larger moduli of rupture for a given amount of clay. It is difficult to tell what the true

TABLE 9. Clay Mineralogy Groups

\begin{tabular}{llr}
\hline Group Name & \multicolumn{2}{c}{ Clay Mineralogy Percentages } \\
\hline Smectite & smectite $\geq 50 \%$ & \\
Mica-smectite & mica $\geq 30 \%$ & $<50 \%$ \\
& $20 \%<$ smectite & $\geq 70 \%$ \\
mica and smectite & \\
mica $\geq 50 \%$ & \\
Kaolinite-chlorite & $\begin{array}{l}\text { smectite } \leq 20 \% \\
\text { kaolinite or chlorite }\end{array}$ & \\
& mica <50\% & \\
& smectite $<50 \%$ & \\
\hline
\end{tabular}



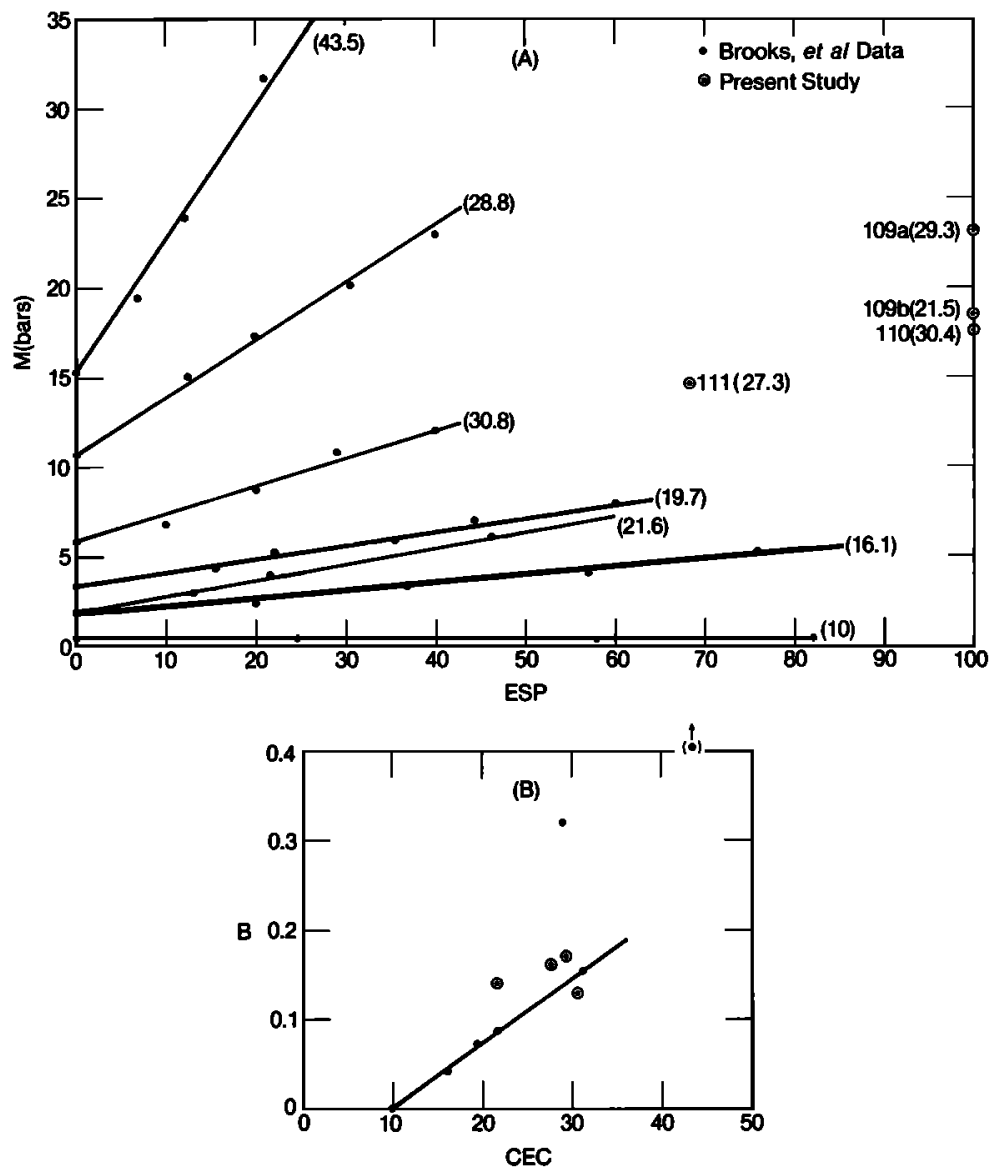

Fig. 2. (a) Modulus of rupture ( $M$ ) versus exchangeable sodium percentage (ESP) for Brooks et al. [1956] data and four samples from the present study. Cation exchange capacity is in parenthesis. $(b)$ Coefficient $B$ of equation (7) versus cation exchange capacity (CEC) for Brooks et al. [1956] data and deviation from equation (5) of modulus of rupture, $M(B)$, divided by ESP for four samples of the present study.

amount of exchangeable sodium is in these samples as the calculated 'exchangeable' sodium contents given in Table 5 exceed the cation exchange capacities; this is apparently due to extremely high quantities of both exchangeable and watersoluble sodium. We suggest, given the data in Table 5, that samples 109a, 109b, and 110 probably have true exchangeable sodium percentages (ESP) near 100 . Therefore, although our data are limited, our findings generally support those of Brooks et al. [1956] and Kemper et al. [1975] on the effect of exchangeable sodium on crust strength. When modulus of rupture versus exchangeable sodium percentage for samples $109 \mathrm{a}, \mathrm{b}, \mathbf{1 1 0}$, and 111 is plotted (Figure $2 a$ ) the agreement with the Brooks et al. data is seen.

The value of $B$ in equation (7) (slope of regression line) is plotted versus cation exchange capacity (CEC) for the Brooks et al. data. The value is seen to be expressable as

$B=0$ for $\mathrm{CEC}<10$

$B=0.00725($ CEC -10$)$ for $10<$ CEC $<30$.

Values for the above four Soda Lake samples of deviation of modulus of rupture from (5) divided by CEC showed agreement with the Brooks et al. data, as is shown in Figure $2 b$.

\section{The Effect of Water-Soluble Material}

The effect of water-soluble material on the modulus of rupture is somewhat unclear. The value of modulus of rupture for compositionally unaltered soils minus the modulus of rupture for soil from which water soluble material had been removed was positive in some cases and negative in others. After examination of the data, it occurred to us that water-soluble material had an effect of cementing the soil and interacted with clay to weaken the clay bonding. The effect of cementation by water soluble material was investigated for the cases in which the clay fraction of total soil mass was less than $30 \%$. For this condition the regression equation expressing change of modulus of rupture $(\Delta M)$ was

$$
\begin{aligned}
\Delta M & =-0.062+0.122 \cdot(\text { salt }) \\
\text { d.f. } & =14 \\
r^{2} & =0.57 \\
\sigma_{\text {res }} & =2.56
\end{aligned}
$$

It should be noted, however, that (8) uses laboratory modulus of rupture. For salt $\%>25 \%$, field modulus $M(F)$ was greater than lab modulus $M(A)$ for the samples from Searles Lake where formation of the crust probably differed greatly from formation in the laboratory. However, for salt \% $<25 \%$, the relationship above is probably consistent with the findings of Nickling and Ecclestone [1981] for artificially added salt on fine sand where the salt was found to cement the surface and increase $U_{* t h}$.

For the case where clay composed more than $30 \%$ of the soil mass, the addition of water soluble material weakened 
the crustal strength. Physically, this was interpreted as a loosening of the clay lamination by crystallization of watersoluble salts. After the cementation effect, (8), was added to $M(A)-M(B)$, the best fitting expression for the effect of water-soluble material was a disability factor to be multiplied by modulus of rupture due to clay and $\mathrm{CaCO}_{3}$ (i.e., $M(B)$ ). This factor was independent of water-soluble salt percentage after it exceeded $0.26 \%$ and was zero for salt $\%<0.26 \%$. Thus, the average disablement factor for seven samples for the effect on clay and $\mathrm{CaCO}_{3}$ by water-soluble material was 0.55 with 1 standard deviation of 0.16 .

\section{The Effect of $\mathrm{CaCO}_{3}$}

The value of $M(B)-M(C)$, when regressed against percentage of calcium carbonate $\left(\mathrm{CaCO}_{3}\right)$, gave a very weak relationship (only $20.7 \%$ of variance explained). The data were divided into two groups: those having $\mathrm{CaCO}_{3}<1.7 \%$ and those having $\mathrm{CaCO}_{3} \geq 1.7 \%$. The group having $\mathrm{CaCO}_{3}$ $<1.7 \%$ showed removal of $\mathrm{CaCO}_{3}$ to have no effect on modulus of rupture. However, the group having $\mathrm{CaCO}_{3}$ $\geq 1.7 \%$ showed a strong relationship between change of modulus of rupture and percentage of clay. The relationship may be expressed as

$$
\begin{aligned}
\Delta M & =0.36+0.033 \cdot \text { (clay) for } \mathrm{CaCO}_{3} \geq 1.7 \% \\
\text { d.f. } & =10 \\
r^{2} & =0.56 \\
\sigma_{\text {res }} & =0.82 \\
\Delta M & =0 \quad \text { for } \mathrm{CaCO}_{3}<1.7 \%
\end{aligned}
$$

These relationships are consistent with the work of Yaalon [1957] who found that $\mathrm{CaCO}_{3}$ often acts as a binding agent but that most of it is present as limestone, dolomite, or calcite particles which are not active as interstitial cementing agents, but which are simply clasts in the soil matrix. The $p H$ values listed in Table 3 show that all the soils are basic and that destruction of mineral or clastic $\mathrm{CaCO}_{3}$ must proceed at a very slow rate.

The interpretation of our data in light of Yaalon's work is that the binding is caused by the solubilization of a small fraction of the $\mathrm{CaCO}_{3}$. Only if the percentage by mass of $\mathrm{CaCO}_{3}$ is greater than 1.7 for our samples does there apparently exist sufficient 'active' $\mathrm{CaCO}_{3}$ to cause binding. The excess $\mathrm{CaCO}_{3}$ exists as inert particles. The size distribution of the soil matrix now determines the magnitude of the effect. If sand is to be bound together, weak bonds are formed because of great pore space and apparently a small amount of 'active' cementation. If clay is to be bound together, however, pore space is smaller and a stronger aggregate is formed.

\section{The Effect of Organic Material}

Desert soils in general are not rich in organic material, and tests of this property were done only for those cases where preliminary inspection showed the presence of significant organic material. Field inspection by one of us (J.A.) did not detect the presence of fungal and algal mats in any of the sampled soils. The regression equation is

$$
\begin{aligned}
\Delta M & =0.1-0.127 \text { (organic\%) } \\
r^{2} & =0.331 \\
\sigma_{\text {res }} & =0.19 \\
\text { d.f. } & =9
\end{aligned}
$$

The correlation coefficient is barely significant, and the relation is felt to give little information. There is some agreement with previous work of Kemper et al. [1975] indicating that "incorporation of organic materials generally decreases crust strength when organic matter has time to decompose.' However, they add that organic matter increases the stability of soil aggregates when they are wetted.

In general, the effect of organic material is very small owing to lack of this material in desert soils, and even when present it does not seem to have a significant effect. It should be noted, however, that the important effects of soil binding by biological growth of mycelia were not duplicated in these laboratory tests and that biological stabilization may be important for many soil crusts [see, for example, Danin and Yaalon, 1981]. For desert crusts where little biological growth was observed, however, we feel justified in ignoring biological and organic effects on the crusts.

\section{An Equation for Modulus of Rupture}

To incorporate all the effects of composition of the soil on the modulus of rupture of the crust, we integrated (4) roughly with the following expression.

$$
\begin{aligned}
M(A)=0.122 \cdot(\text { salt }) & +\left(\begin{array}{c}
0.45 \text { (for salt }>0.26) \\
1 \text { (for salt }<0.26)
\end{array}\right) \\
\cdot & \left\{\left[\begin{array}{l}
0.08 \text { (for non mica) } \\
0.0076 \text { (for mica) }
\end{array}\right)\right. \\
+ & \left.\left(\begin{array}{c}
\left.0.033 \text { (for } \mathrm{CaCO}_{3}>1.7 \%\right) \\
\left.0 \text { (for } \mathrm{CaCO}_{3}<1.7 \%\right)
\end{array}\right)\right] \\
& \cdot \text { clay }+B \cdot \mathrm{ESP}\}
\end{aligned}
$$

where

$$
B=\left(\begin{array}{c}
0 \text { for } \mathrm{CEC}<10 \\
0.00725(\mathrm{CEC}-10) \text { for } 10<\mathrm{CEC}<30)
\end{array}\right)
$$

The equation explained $51 \%$ of the variance when sample 104 was removed and $39 \%$ for all of the data for which $M(A)$ $>2 \sigma_{A}$. The data sets contained 34 and 35 values with residual standard deviations of 2.4 and 3.0 bars, respectively. The equation thus seems to predict modulus of rupture for soils with salt $<45 \%$ to a fair degree. Broadly, it states that the most important variable for crustal strength for most soils is percentage of clay.

\section{Additional Considerations}

\section{Relationship of Thickness of Crust to Soil Composition}

Correlation coefficients for crust thickness versus composition parameters are given in Table 10. No significant correlations were found except for $\mathrm{CaCO}_{3}$ for which the coefficient was only $\mathbf{0 . 4 5 5}$. It is the opinion of the authors that crustal thickness is a function of soil wetting and drying which is only partially a function of composition (e.g., permeability of soil, wetting front velocity). Wetting and drying would be explained by amount and frequency of moisture and of rate of evaporation for which we had no information. Therefore, we cannot generalize on crustal thickness. 
TABLE 10. Correlation Coefficients for Soil Composition Parameters With Crust Thickness

\begin{tabular}{lcc}
\hline $\begin{array}{c}\text { Composition } \\
\text { Parameter }\end{array}$ & $\begin{array}{c}\text { Correlation } \\
\text { Coefficient }\end{array}$ & $\begin{array}{c}\text { Degrees of } \\
\text { Freedom }\end{array}$ \\
\hline \% salt & $0.04^{*}$ & 33 \\
\% clay & $0.19^{*}$ & 33 \\
\% clay (non smectite) & $0.26^{*}$ & 33 \\
\% $\mathrm{CO}_{3}$ & 0.46 & 33 \\
\% organic & $0.42^{*}$ & 17 \\
\hline
\end{tabular}

*Not significant.

\section{Curled or Flat Soil Crust}

Crust having more than $22 \%$ clay of at least $3 / 10$ Smectite mineralogy were curled with only two exceptions: Sample 111 and 314 were flat. The remaining soils were also flat. This property affects threshold friction velocity; it is easier to break a curled crust.

\section{Special Mechanisms Making Soils Erodible}

Aside from the general relationships given above for the wind erosion potential of clay rich soils, four special cases were observed:

1. Cracking of clay into peds small enough to erode. Cracking of clay to pellets as small as 1 to $5 \mathrm{~mm}$ diameter was observed in dry lakes of west Texas. Such clay aggregates of sand and gravel size have also been described by Blackwelder [1946] and Roth [1960].

2. Peeling of thin clay crusts. Following an infrequent heavy rainfall, water may accumulate on the low-permeable surface of a dry lake. Wave action of the water disturbs the soil and suspends some of it. During calm conditions coarse particles settle leaving fine clay in suspension. After the water evaporates a clay film is deposited which will curl. Observations of erosion of such clay curls at Emerson Dry Lake and Soggy Dry Lake in the Mojave Desert support similar observations made by Kemper et al. [1975].

3. Foam. Following an infrequent heavy rainfall, the accumulation of water in a dry lake bed may be wind-wave action liberate organic material and clay which accumulates on the leeward shore of the lake. This foam which is high in organic material [Gillette et al., 1980] is highly erodible when dry. We witnessed the erosion of such foam at Soggy Lake in 1978.

4. 'Salt blisters.' We observed blisterlike domes on the salty-clay crust of Soda Dry Lake (109). Several of the domes had split open, (e.g., 110), exposing loose, dry soil within, which was highly erodible.

\section{Discussion}

The above relationships show that undisturbed soils are effectively protected even by weak soil crusts $(M=0.7$ bars and larger) so long as loose particles are not present on the surface. If loose particles are on the surface, the movement of these particles during high winds acts quickly to break up weak soil crusts. Strong soil crusts may withstand the disintegrating blows of sand and gravel proportionately to their moduli of rupture.

Since crusts are broken into smaller aggregates proportional to modulus of rupture times (thickness of crust) ${ }^{2}$ it stands to reason that the lowering of $U_{* \text { th }}$ is proportional to the magnitude of the disturbance. Put in another way, modulus of rupture times (thickness of crust) ${ }^{2}$ is proportional to the impressed force that causes the rupture.

When a limiting value is exceeded, the crust is broken into smaller pieces. It follows, then, that a rough approximation might be made for estimating $U_{* \text { th }}$ for disturbances different from those of our investigation.

$U_{* t h}$ (adjusted) $=\left(\frac{\text { our impressed force }}{\text { adjusted impressed force }}\right)$

$$
\cdot U_{* \text { th }} \text { (equation (3)) }
$$

Our impressed force was applied by the accelerating snow and mud tires of a one-quarter-ton pickup truck. Equation (12) would then predict a lower $U_{\text {*th }}$ for a more severe disturbance and a higher $U_{* \text { th }}$ for a less severe disturbance. For reduced impressed forces we would also expect a smaller value for thickness for which disturbance causes only a minute amount of fine material to be loosened on the surface with the remainder of the crust unaffected.

\section{Conclusions}

1. For undisturbed soils, even a weak crust (modulus of rupture $\geq 0.7$ bar) will protect the soil from wind erosion for all but extremely high winds.

2. A disturbed soil will be highly erodible if the undisturbed crust has modulus of rupture $\leq 1$ bar.

3. Disturbed soils with undisturbed modulus of rupture $>2$ bars will have threshold velocity roughly proportional to modulus of rupture times (thickness of crust) ${ }^{2}$.

4. Modulus of rupture of a crust is proportional to percentage of clay, but mica clay is weaker than other clays. Percentage of clay is probably the most important variable in crust strength.

5. Higher percentage of exchangeable sodium strengthens the crust.

6. $\mathrm{CaCO}_{3}$ strengthens the crust proportional to percentage of clay.

7. Organic materials seem to make no difference in crust strength in the desert soils tested, but recognition of biological effect was not possible with our methods.

8. Soil composition did not provide any good predictors of crust thickness.

Acknowledgments. The authors are happy to acknowledge Gerald Dolan, who built and helped operate the portable wind tunnel. We thank the National Center for Atmospheric Research for the use of its anemometer calibration facility and the wind tunnel. The sedigraph was purchased for the University of Colorado by NSF grant EAR-7823693. Warren Lynn of the U.S.D.A. National Soil Laboratory in Lincoln, Nebraska, gave helpful suggestions and determined exchangeable cation percentage and CEC for four soil samples. The Department of Geological Sciences, University of Colorado, allowed us use of its $\mathrm{X}$ ray diffractometer.

\section{REFERENCES}

Blackwelder, E., Evolution of desert playas (abstract), Geol. Soc. Am. Bull., 57, 1179, 1946.

Brooks, R. H., C. A. Bower, and R. C. Reeve, The effect of various exchangeable cations upon the physical condition of soils, Soil Sci. Soc. Am. Proc., 20, 325-327, 1966.

Buckman, H. O., and N. C. Brady, The Nature and Properties of Soils, 7th Ed., Macmillan, New York, 1969.

Carroll, D., Clay minerals: A guide to their $\mathrm{X}$-ray identification, Geol. Soc. Amer. Spec. Pap. 126, 1970. 
Chao, C. Y., $2 \theta(\mathrm{Cu})$ table for common minerals, Pap. 69-2, Dept. of Geol., Carleton Univ., Ottawa, Canada, 1969.

Chapman, H. D., Cation-exchange capacity, in Agronomy, 9, 891901,1965 .

Chepil, W. S., Influence of moisture on erodibility of soil by wind, Soil Sci. Am. Proc., 20, 288-292, 1956.

Danin, A., and D. H. Yaalon, Trapping of silt and clay by lichen and bryophytes in the desert environment of the Dead Sea region (abstract), Int. Conf. Aridic Soils Abstracts, 29, 1981.

Draper, N. R., and H. Smith, Applied Regression Analysis. John Wiley, New York, 1966.

Gillette, D., Tests with a portable wind tunnel for determining wind erosion threshold velocities, Atmos. Env., 12, 2309-2313, 1978.

Gillette, D., J. Adams, A. Endo, D. Smith, and R. Kihl, Threshold velocities for input of soil particles into the air by desert soils, $J$. Geophys. Res., 85, 5621-5630, 1980.

Jackson, M. L., Soil Chemical Analysis-Advanced Course, published by the author, Dept. of Soil Science, Univ. of Wisconsin, Madison, Wisconsin.

Kemper, W. D., D. Evans, and H. Hough, Crust strength and cracking: 1, Strength, Tech. Bull. 214, Agricul. Experiment Station, Univ. of Arizona, Tucson, 1975.
Lettau, H., Note on aerodynamic roughness-Parameter estimation on the basis of roughness element description, J. Appl. Meteorol., $5,828-832,1969$.

Nickling, W. G., and M. Ecclestone, The effects of soluble salts on the threshold shear velocity of fine sand, Sedimentology, 28, 505$510,1981$.

Priestley, C. H. B., Turbulent Transfer in the Lower Atmosphere, University of Chicago Press, Chicago, Ill., 1959.

Richards, L. A., Modulus of rupture as an index of crusting of soil, Soil Sci. Soc. Am. Proc., 17, 321-323, 1953.

Roth, E. S., The silt-clay dunes at Clark Dry Lake, California, Compass, 38, 18-27, 1960.

Wooding, R. A., A low-speed wind tunnel for model studies in micrometeorology, I, General design considerations, Tech. Pap. 25, pp. 3-214, C.S.I.R.O. Austr. Div. Plant Ind., Canberra City, A.C.T., 1968.

Yaalon, D., Problems of soil testing on calcareous soils, Plant Soil, 8, 275-288, 1957.

(Received December 22, 1982; revised July 19, 1982; accepted July 22, 1982.) 